'Departamento de Pesquisa, Instituto Agronômico de Pernambuco (IPA) Av. General San Martin, 1371, Bongi, CEP 50761-000, Recife, PE, Brasil ${ }^{2}$ Embrapa Solos, Unidade de Execução de Pesquisa e Desenvolvimento de Recife (UEP Recife), Recife, PE, Brasil

* autor correspondente

凶antonio.raimundo@ipa.br

\title{
Aptidão agrícola das terras do município de Buenos Aires, Pernambuco
}

\author{
Land agricultural fitness of the municipality of Buenos Aires, \\ State of Pernambuco, Brazil
}

Antonio Raimundo de Sousa ${ }^{*}$, Ademar Barros da Silva² ${ }^{2}$ Fernando Antônio Távora Gallindo', Vital Artur de Lima e Sán', José Nunes Filho', Luciano José de Oliveira Accioly²

RESUMO: Os ecossistemas do município de Buenos Aires, situado na Zona da Mata de Pernambuco, apresentam características especiais, sobretudo no tocante à utilização e ao manejo dos solos. Nesse sentido, a classificação da aptidão agrícola das terras deve refletir, fielmente, as potencialidades e as limitações ambientais, o que é de fundamental importância para orientação do manejo local. Este trabalho teve como objetivo determinar, com base no levantamento de solos (escala 1:25.000), a aptidão agrícola das terras do município de Buenos Aires, PE, visando subsidiar o planejamento das atividades rurais. No levantamento, foram consideradas as seguintes características dos solos: deficiência de fertilidade; deficiência de água; excesso de água ou deficiência de oxigênio; suscetibilidade à erosão e impedimento à mecanização. As classes de aptidão foram definidas como boa, regular, restrita e inapta. As terras do município foram enquadradas em quatro grupos e seis subgrupos. Os resultados obtidos permitem verificar que as terras do grupo 1 (5,90\% da área estudada) enquadram-se na classe de aptidão boa para lavouras nos níveis de manejo pouco desenvolvido e desenvolvido e classe restrita em nível de manejo primitivo. Para o grupo 2, que concentra a maior parte da área $(53,94 \%)$, foram identificadas terras com aptidão regular para lavouras nos manejos primitivo e pouco desenvolvido. O grupo 4 , com $28,53 \%$ da área, apresenta terras consideradas de utilização boa e regular para pastagens plantadas. O grupo 5 , que ocupa $11,63 \%$ das terras do município, apresenta aptidão boa para silvicultura e restrita para pastagens naturais. Considerando-se que existem terras com diversos indicativos de uso, entre os quais lavouras, pastagens, silvicultura e preservação ambiental, sugere-se que o planejamento de uso das terras permeie o planejamento das atividades do setor primário com foco na sustentabilidade do município.

PALAVRAS-CHAVE: Uso do solo, sustentabilidade ambiental, potencial agrícola.
ABSTRACT: Agricultural fitness classification of soils is elaborated according to potentialities and environmental limitations, thus, it is of fundamental importance to the guidance of sustainable management of related ecosystems. The main purpose of this research was to determine, based on soil survey (scale 1:25.000), the land agricultural fitness of Buenos Aires county, State of Pernambuco, in order to support agricultural activities planning. The following soil characteristics were considered: fertility and water deficiencies, water excess or aeration deficiency, erosion susceptibility, and impediments to mechanization. Fitness classes were defined as good, regular, restrict and unable, reflecting the intensity that limiting factors affect lands. Lands of this municipality were classified in four groups and six subgroups: group I, with one subgroup, occupies around 5.9\%, with Argissoils association (yellow and red-yellows), with soils from a subgroup without physical impediment and relief plan, soft wavy; and the other showing relief plan, stony. The two subgroups of group 2 totalize $53.94 \%$, predominating deep Red Argissoils and Red-Yellow with good fertility and well drained. Group 4 comprises tree subgroups, with $28.53 \%$, with Neossoils Litolics, Haplics Plans soils and Haplics Gleissoils, presenting several limitations for cropping use. Group 5 occupies only 11.63\%, with deep and poor-deep Argissoils and hard wavy relief. Considering that there are areas in this municipality with several indicatives (crops, pasture, forestry and environment preservation), it is essential that environmental planning pervade the main activities of the primary sector.

KEYWORDS: Use of soils, environmental sustainability, agriculture potentiality. 


\section{Introdução}

A principal atividade agrícola do município de Buenos Aires é o cultivo de cana-de-açúcar, cultura que se desenvolve desde o século XVI. Outros cultivos, como banana, acerola, milho, inhame, mandioca e hortaliças folhosas, são encontrados em pequenas áreas (JACOMINE et al., 1972, 1973; INSTITUTO..., 2001). No setor pecuário, há um destaque para a atividade de bovinocultura. Apesar disso, o uso e a ocupação do solo ocorrem de forma desorganizada. Essa ocupação desordenada em distintos setores ambientais do município, desconsiderando suas potencialidades e limitações, favorece o desencadeamento de processos erosivos, promovendo as ações de degradação que, indiscriminadamente, prejudicam toda a comunidade.

A região foi, outrora, encoberta pela Mata Atlântica que apresentava exuberância e heterogeneidade. As atividades humanas ali instaladas reduziram de forma paulatina a cobertura vegetal existente, desde a chegada dos colonizadores portugueses que se instalaram prioritariamente na zona litorânea do estado. Assim, desde o século XVI, a ocupação do solo esteve relacionada com a exploração da cana-de-açúcar em pequenos engenhos (ANDRADE-LIMA, 1970; SOUSA et al., 2007).

A retirada da vegetação original se iniciou pelas várzeas e áreas planas, devido à facilidade de acesso. Posteriormente, os engenhos foram absorvidos pelas usinas que passaram a produzir maior quantidade de cana-de-açúcar, tendo como consequência maior devastação da vegetação natural. $\mathrm{O}$ desenvolvimento das usinas intensificou a demanda de cana-de-açúcar por novas áreas de plantio, levando à ocupação das encostas de forma indiscriminada, sem que fossem consideradas as potencialidades e limitações desses ambientes.

No planejamento das atividades agropecuárias, deve-se considerar a potencialidade das unidades de solo, buscando-se reduzir os fatores restritivos e contemplar seu uso e manejo por meio da aplicação de tecnologias relacionadas com a aptidão agrícola dessas terras. Isso possibilita maior rendimento das culturas e assegura a sustentabilidade dos diversos ambientes trabalhados.

Este trabalho foi desenvolvido objetivando-se a interpretação do levantamento de solos e a classificação do potencial agrícola das terras desse município, disponibilizando-se informações indispensáveis ao planejamento agroambiental dos sistemas produtivos locais.

\section{Material e Métodos}

O município de Buenos Aires, onde foi realizado o presente trabalho, está localizado na microrregião setentrional da Mata Pernambucana, com distância aproximada de $80 \mathrm{~km}$ da capital do estado. Ocupa uma área de $111 \mathrm{~km}^{2}$, com população em torno de 14.000 habitantes, tendo como principais atividades o cultivo de cana-de-açúcar, a agricultura familiar (hortaliças folhosas, feijão, milho e mandioca) e a pecuária bovina. A cobertura vegetal original dessa área é classificada como floresta subcaducifólia, atualmente com poucos remanescentes (JACOMINE et al., 1973; INSTITUTO..., 2001).
Com relação ao clima, de acordo com a sistemática de Köppen, prevalece o tipo As', ou seja, tropical chuvoso, com chuvas concentradas nos meses de abril a julho (JACOMINE, et al., 1973) e a pluviosidade média anual de $1.175 \mathrm{~mm}$.

A formação geológica de grande parte da área é de rochas cristalinas do Pré-cambriano indiviso, constituídas por gnaisse com biotita e granito (JACOMINE, et al., 1973). A região é composta por topografia dominada por vales em forma de $\mathbf{V}$ e encostas com declividades entre $10 \%$ e $40 \%$. $\mathrm{O}$ relevo varia de plano a forte ondulado, com alguns locais apresentando problemas de erosão. As áreas com relevos plano e suave ondulado estão restritas aos topos esparsos, estreitos e compridos e às planícies fluviais (INSTITUTO..., 2001) e Silva et al. (2001).

Cartas planialtimétricas na escala 1:25.000 e com curvas de nível com $10 \mathrm{~m}$ de altura foram utilizadas como material cartográfico básico nos estudos de solos, tudo de acordo com metodologias propostas por Embrapa (1995), Santos et al. (2005) e Embrapa (2006).

A classificação da aptidão agrícola das terras foi realizada com base nos resultados do trabalho de levantamento de solos do município, na escala 1:25.000, (SOUSA et al., 2007). Os critérios utilizados na classificação foram os sugeridos por Ramalho Filho e Beek (1994). O sistema tem caráter interpretativo, possibilitando a avaliação do potencial das terras para lavouras, pastagens, silvicultura e preservação da flora e da fauna.

O processo de avaliação da aptidão agrícola das terras no município foi realizado levando-se em conta os diferentes tipos de manejo agrícola localmente adotados e o grau de limitação dessas atividades. No que se refere à avaliação das condições agrícolas das terras, consideraram-se os seguintes fatores de limitação de uso dos solos: deficiência de água, deficiência de oxigênio ou excesso de água, deficiência de fertilidade, suscetibilidade à erosão e impedimento à mecanização. $\mathrm{Na}$ avaliação dos diferentes fatores de limitação do solo, foram considerados os graus: nulo, ligeiro, moderado, forte, muito forte e extremamente forte.

Quanto às práticas agrícolas, foram estabelecidos os seguintes níveis de manejo: A (primitivo), B (pouco desenvolvido) e C (desenvolvido - alto nível tecnológico).

Entre os grupos de aptidão, os de números 1, 2 e 3 são os melhores para lavouras, conforme os níveis de manejo. Os grupos 4 e 5 identificam áreas para pastagem plantada e silvicultura e/ou pastagem natural, respectivamente. O grupo 6 identifica as áreas para preservação da flora e da fauna.

As classes de aptidão, definidas como boa, regular, restrita e inapta, para cada tipo de uso, evidenciam e são consequência da intensidade com que as limitações afetam as terras, podendo ser um indicativo dos novos manejos a serem adotados.

\section{Resultados e Discussão}

Os resultados da avaliação da aptidão agrícola das terras no município de Buenos Aires podem ser observados na Tabela 1 e na Figura 1. O sistema de avaliação classificou quatro grupos 
Tabela 1. Unidade de mapeamento de solo, grupo, subgrupo, área e percentual das classes de aptidão agrícola das terras, município de Buenos Aires, PE

\begin{tabular}{cccccc}
\hline Unidade de mapeamento de solo* & Grupo & Subgrupo** & Área $\left(\mathbf{k m}^{2}\right)$ & \% da área total \\
\hline PVA1 & 1 & 1 ”aBC & 6,60 & 40,70 & 36,41 \\
PVA2 & 2 & $2 \mathrm{a}(\mathrm{b})$ & 10,60 & 9,48 \\
PV1 & 2 & $2 \mathrm{a}(\mathrm{b})$ & 9,00 & 8,05 \\
PVA3 & 2 & $2 \mathrm{ab}(\mathrm{c})$ & 6,90 & 6,17 \\
RL & 4 & $4 \mathrm{P}$ & 3,60 & 3,22 \\
SX & 4 & $4 \mathrm{P}$ & 21,40 & 19,14 \\
GX & 4 & $4 \mathrm{p}$ & 13,00 & 11,63 \\
PV3 & 5 & $5 \mathrm{~S}(\mathrm{n})$ & & 11,80 & 100,00 \\
\hline Total & & & & \\
\hline
\end{tabular}

*PVA = Argissolo Vermelho-Amarelo; PV = Argissolo Vermelho; RL = Neossolo Litólico; SX = Planossolo Háplico; GX = Gleissolo Háplico.

**Ver Legenda do Mapa na Figura 1.

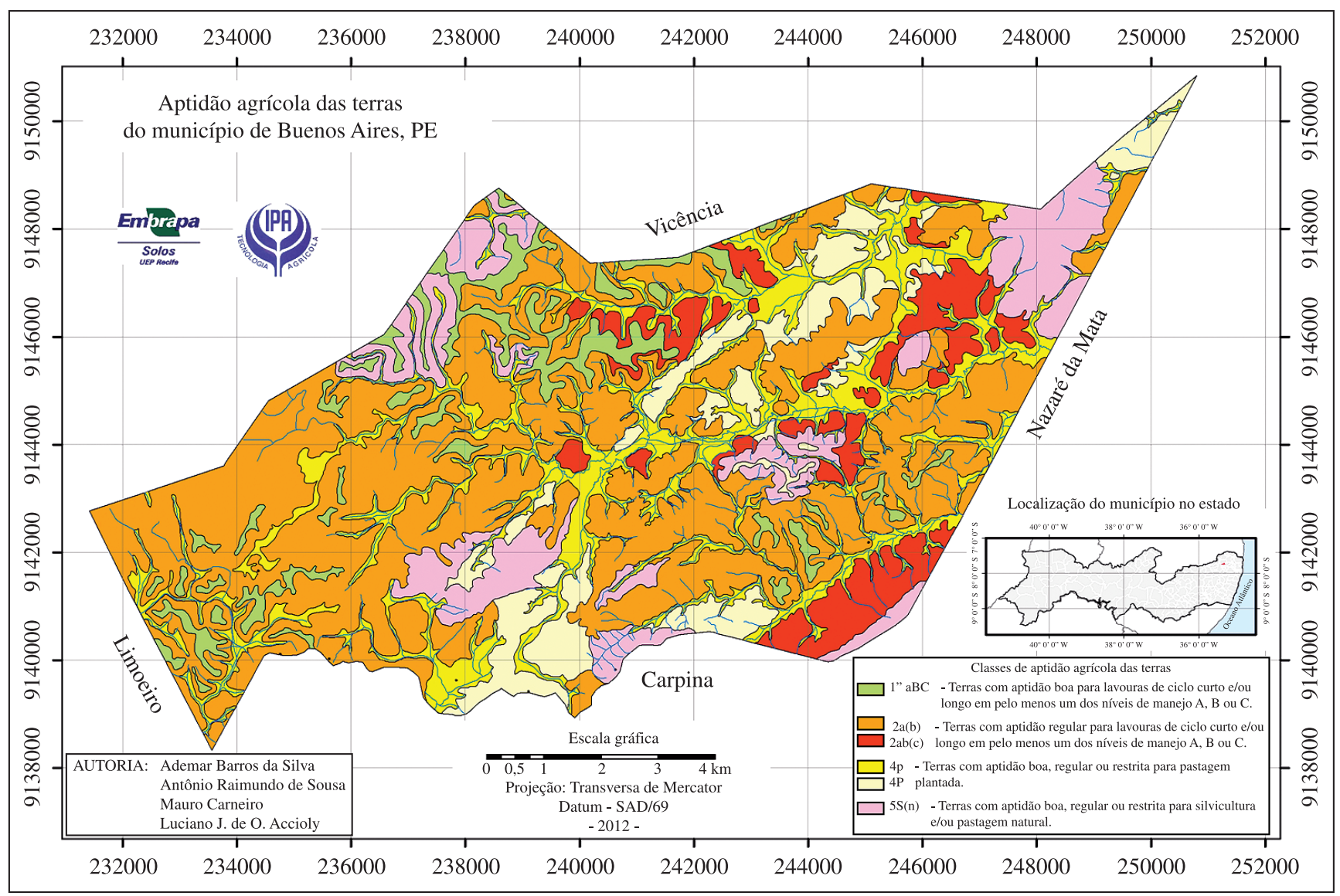

Figura 1. Aptidão agrícola das terras do município de Buenos Aires, Pernambuco.

e seis subgrupos de aptidão que foram obtidos de acordo com os diferentes tipos de manejo e graus de limitação.

As terras do subgrupo 1"aBC ocupam 6,60 km² (Tabela 1) e são classificadas como de aptidão boa para lavouras nos níveis de manejo pouco desenvolvido (B) e desenvolvido (C) e aptidão restrita no nível de manejo primitivo (A), que correspondem aos Argissolos Vermelho-Amarelos eutróficos e distróficos. São solos muito profundos, friáveis, sem impedimento de drenagem, situados em relevo plano e suave ondulado e que têm como limitação a deficiência na fertilidade natural. Essa limitação conduz à necessidade de investimentos em corretivos e fertilizantes, enquadrando essas terras consequentemente na classe de aptidão restrita, quando se considera o nível de manejo primitivo. Vale ressaltar que nessas áreas é possível fazer dois cultivos por ano, desde que com o uso de irrigação e com os devidos cuidados com relação à potencialidade de cada sistema produtivo local. 
No grupo 2, tem-se o subgrupo 2a(b) que abrange $51,30 \mathrm{~km}^{2}$, sendo classificado como de aptidão regular, no nível de manejo primitivo, e restrita, no manejo pouco desenvolvido. Nessa área, predominam os Argissolos Vermelhos e VermelhoAmarelos, ambos distróficos, necessitando de correção quanto à acidez e fertilidade natural. Outros fatores restritivos são o relevo ondulado e forte ondulado e, algumas vezes, a pouca profundidade efetiva do solo. As culturas devem ser concentradas nas áreas de relevo ondulado, desde que utilizadas práticas de controle de erosão. Por outro lado, as terras do subgrupo $2 \mathrm{ab}(\mathrm{c})$ ocupam uma área de $9,00 \mathrm{~km}^{2}$ e são consideradas de uso regular, nos níveis de manejo primitivo e pouco desenvolvido, sendo avaliadas como de uso restrito no manejo desenvolvido. Nessas terras, estão incluídos os Argissolos Vermelho-Amarelos e Vermelhos, tendo como principais limitações o relevo ondulado e a baixa fertilidade do solo. As áreas de relevo forte ondulado e montanhoso devem ser usadas para preservação da fauna e da flora.

No grupo 4, encontram-se o subgrupo $4 \mathrm{P}\left(10,50 \mathrm{~km}^{2}\right)$, com classe de aptidão boa para pastagens plantadas, e o subgrupo $4 \mathrm{p}\left(21,40 \mathrm{~km}^{2}\right)$, com aptidão regular para pastagens plantadas. Nessas áreas, ocorrem Neossolos Litólicos, Planossolos e Gleissolos que apresentam como limitações a baixa profundidade efetiva nos Neossolos Litólicos e a drenagem deficiente nos Planossolos e Gleissolos. Para o subgrupo 4P, têm-se, também, os Neossolos Litólicos e os Planossolos Háplicos solódicos de relevo plano e suave ondulado que, em alguns casos, apresentam como maior limitação a pouca profundidade, quase sempre associada à pedregosidade. Salienta-se que o relevo, em algumas áreas, apresenta-se muito movimentado, entretanto, predomina o relevo plano e suave ondulado. O subgrupo $4 \mathrm{p}$ tem terras consideradas de utilização regular para pastagens plantadas. Correspondem aos solos de baixadas fluviais, planas e suave onduladas, envolvendo os Gleissolos Háplicos eutróficos solódicos, com relevo plano e suave ondulado. Embora essas áreas sejam tradicionalmente consideradas de bom potencial para agricultura e bastante explorada, especialmente com cana-de-açúcar, constatou-se um elevado nível de sodicidade e/ou salinidade, mesmo quando há utilização de drenagem. Muitas dessas áreas já foram abandonadas em função da baixa produtividade registrada, consequência das limitações mencionadas. Como são áreas de extrema variabilidade espacial em solos, são necessários estudos e levantamentos mais detalhados para averiguação da extensão desses fatores adversos e avaliação das possibilidades de correção, buscando-se a recuperação dos índices de produtividade dessas terras.

Para o grupo 5, subgrupo 5S(n), com 13,00 $\mathrm{km}^{2} \mathrm{de}$ abrangência, os solos foram classificados como de aptidão boa para silvicultura e restrita para pastagens naturais. Essa unidade, embora envolvendo Argissolos Vermelhos e Vermelho-Amarelos predominantemente profundos, tem como fator restritivo o relevo, que vai de forte ondulado a montanhoso.

\section{Conclusões}

- O município dispõe de 660 ha de terras com aptidão boa para lavouras nos níveis de média e alta tecnologia, porém com necessidade de adoção de práticas adequadas de manejo e conservação de solos.

- Foram identificados 6.030 ha de aptidão regular e restrita, para lavouras no manejo primitivo, pouco desenvolvido e desenvolvido, apresentado-se como fatores restritivos o relevo forte ondulado, a pouca profundidade efetiva, a baixa fertilidade e a elevada acidez do solo.

- Registrou-se um total de 3.190 ha de solos com classe de aptidão boa e regular para pastagens. Entretanto, deve ser estreitamente observada a capacidade de suporte animal dessas áreas, como precaução para o controle da degradação ambiental.

- Outros 1.300 ha foram identificados como terras consideradas de aptidão boa para silvicultura e restrita para pastagens naturais.

\section{Referências}

ANDRADE-LIMA, D. Recursos vegetais de Pernambuco. Recife: IPA, 1970. 32 p. (IPA. Boletim Técnico, n. 41).

EMBRAPA. Centro Nacional de Pesquisa de Solos. Procedimentos normativos de levantamentos pedológicos. Brasília: Embrapa Produção de Informação, 1995. 101 p

EMBRAPA. Centro Nacional de Pesquisa de Solos. Sistema brasileiro de classificação de solos. 2. ed. Rio de Janeiro: Embrapa Solos, 2006. 306 p.

INSTITUTO AGRONÔMICO DE PERNAMBUCO - IPA. Zoneamento agroecológico dos municípios da Zona da Mata de Pernambuco. Recife: IPA/PROMATA, 2001.v. 1,91 p. (Relatório Técnico Descritivo).

JACOMINE, P. K. T. et al. Levantamento exploratórioreconhecimento de solos do estado de Pernambuco. Recife: DNPEA/SUDENE-DRN, 1972. v. 2, 312 p. (DNPEA. Boletim Técnico, n. 26; SUDENE-DRN. Série Pedologia, n. 14).

JACOMINE, P. K. T. et al. Levantamento exploratórioreconhecimento de solos do estado de Pernambuco. Recife: DNPEA/SUDENE-DRN, 1973. v. 1, 359 p. (DNPEA. Boletim Técnico, n. 26; SUDENE-DRN. Série Pedologia, n. 14).

RAMALHO FILHO, A.; BEEK, K.J. Sistema de avaliação da aptidão agrícola das terras. 3. ed. rev. Rio de Janeiro: EmbrapaCNPS, 1994. 65 p.

SANTOS, R. D. et al. Manual de descrição e coleta de solo no campo. 5. ed. Viçosa: Sociedade Brasileira de Ciência do Solo, 2005. 92 p.

SILVA, F. B. R. et al. Zoneamento agroecológico do Estado de Pernambuco. Recife: Embrapa Solos UEP Recife, Secretaria de Produção Rural e Reforma Agrária, 2001. 1 CD-ROM. (Embrapa Solos. Documentos, n. 35).

SOUSA, A. R. et al. Caracterização dos principais solos do município de Buenos Aires, Pernambuco. In: CONGRESSO BRASILEIRO DE CIÊNCIA DO SOLO, 31., 2007, Gramado. Anais... Gramado: Sociedade Brasileira de Ciência do Solo, 2007. 1 CD-ROM. 